\title{
The Good of the Few: Reciprocal Acts and the Provision of a Public Bad
}

\author{
Jason Delaney \\ School of Business \\ Georgia Gwinnett College \\ 1000 University Center Lane \\ Lawrenceville, GA 30043 \\ jdelaney@ggc.edu \\ Phone: +1-501-569-8874
}

\author{
Sarah Jacobson $^{1}$ \\ Department of Economics \\ Williams College \\ 24 Hopkins Hall Dr. \\ Williamstown, MA 01267 \\ Sarah.A.Jacobson@williams.edu \\ Phone: +1-413-597-4766
}

June 2015

\begin{abstract}
:
People trade favors when doing so increases efficiency. Will they when it reduces efficiency, such as in political logrolling? We introduce the "Stakeholder Public Bad" game, in which common fund contributions increase one person's earnings (the "Stakeholder") while reducing others' earnings and overall efficiency. The Stakeholder position rotates through all group members or just alternates among two people (making it easier to form a coalition). High Stakeholder rewards provide a lever for reciprocity: if someone contributes when another is Stakeholder, he may be rewarded with a gift when he becomes Stakeholder. Reciprocity is only possible when agents know others' roles and actions, so information provision may be pro- or anti-social. In a laboratory experiment, we combine a rotating or alternating asymmetry in payoffs with varying levels of information provision to examine pro- and anti-social reciprocity. We find that subjects in the Stakeholder role willingly sacrifice social welfare. We also see both anti-social and pro-social favor trading, particularly when coalition-forming is easier. Favor trading does not change the mean level of public bad provision. People who trade favors tend to be less risk averse.
\end{abstract}

JEL codes: H41, D01, D62, D64, D70, C91

Keywords: reciprocity, public bad, logrolling, social preferences, externalities, public good

\footnotetext{
${ }^{1}$ Corresponding author. The authors are grateful for funding from NSF Award SES-0752754 and support from Williams College. For helpful input and comments we also thank Robert Gazzale, Cary Deck, Angela de Oliveira, two anonymous referees, and participants in various seminars and presentations, including at Williams College, University of Arkansas, and the Economic Science Association.
} 


\section{Introduction}

People must often decide whether to support a policy that has both winners and losers. A defense contract benefits one constituency while incurring large tax-funded expenses; a factory siting decision brings jobs to one area but has broad environmental consequences; an appropriations bill funds wasteful "bridges to nowhere" to the benefit of individual committee members. Further, these groups must often repeat the decision process with different stakeholders for different projects. This structure may give rise to reciprocal behavior: you support my project and I'll support yours. Cohen and Malloy (2014) document this type of reciprocal behavior in United States Senate votes and earmarks. Favor trading may take the form of explicit quid pro quo arrangements as in corruption or nepotism, or people may implicitly expect reciprocation as when pharmaceutical representatives who give gifts to doctors expect (and see) increased prescriptions of their drugs (Wazana, 2000). Existing evidence (Jacobson and Petrie, 2014) shows that favor trading can increase provision of pro-social projects. We investigate whether the same dynamic occurs when a project is anti-social—when the harm it causes within a group exceeds the benefit it generates. If it does, then reciprocity, long championed as a force for good, can be destructive, and so can the information that enables it.

We create a novel model of anti-social favor trading, and test the model using lab experiments. Our “Stakeholder Public Bad” game allows reciprocal behavior in a group’s provision of a project with heterogeneous costs and benefits. In each round, each member of a group decides how much to contribute to a common fund. These contributions determine the provision of an efficiency-reducing project in which one member has a stake (i.e., a financial interest) and which reduces other members’ payoffs. These projects are like a series of bills or earmarks that each have a proponent who benefits if it passes but have social costs that outweigh 
those benefits. The Stakeholder role rotates so different group members periodically become the project beneficiary. A two-player coalition can benefit by reciprocally "helping” each other but there is no coalition enforcement mechanism. We vary the availability of information necessary for reciprocity and whether the circle of potential reciprocators (those who will be Stakeholder) includes all group members or just a two-person subset of the group (making it easier to form a coalition).

How people behave in such a game depends on their social preferences and whether they expect reciprocation. To explore this behavior, we implement the game in a lab experiment. We find that subjects contribute nearly fully in the role of Stakeholder, even though this is antisocial. Most importantly, people engage in anti-social reciprocation by "helping” the current Stakeholder in hopes of being reciprocally helped in the future and to repay past help. They do this even though average reciprocation is not high enough to make this profitable. However, we also find another avenue of reciprocity: when a pair is nudged into a coalition by shrinking the circle of reciprocity, favor trading also occurs through reduced Stakeholder contributions, and this is pro-social. Finally, we find that people who trade favors in both routes of reciprocity are on average less risk averse, which is consistent with favor-trading being a risky strategy.

Our results show that reciprocal acts need not always increase welfare. Further, since some reciprocal acts are anti-social, and since reciprocity depends on information about people's actions and payoffs, our results also show that information provision can be anti-social.

\section{Favor trading in Public Good and Public Bad Provision}

Our study builds on an extensive literature on public goods (useful surveys of which include Chaudhuri, 2011; Ledyard, 1995) that shows that subjects behave far more pro-socially than predicted by models of fully self-interested optimizing behavior. Motives for this 
cooperation may include fairness (e.g., Marwell and Ames, 1981), altruism (e.g., Dawes, 1980), and conditional cooperation (Gächter, 2007). ${ }^{2}$ Many provision institutions have been studied. Most relevant is the linear voluntary contributions mechanism, in which contributions to a common fund have constant returns to each member of a group. We create a novel model, the Stakeholder Public Bad game, built on the voluntary contributions game but modeling public bads instead of public goods and allowing favor trading.

Projects that reduce efficiency have received less attention, in part because many models treat public bads as dual to public goods. For example, one can argue that preferences against (the public bad of) pollution are like preferences for (the public good of) pollution abatement. ${ }^{3}$ However, public bads merit direct study because people act differently when a game is framed as public good provision rather than public bad reduction. Schwartz-Shea (1983), Andreoni (1995b), and Sonnemans et al. (1998) show that people behave more pro-socially in public good than public bad framing. ${ }^{4}$ The public bad literature yields other lessons: Barr and Serra (2009, 2010) find that culture and the size of social costs affect willingness to contribute to a public bad; work by Moxnes and van der Heijden (Moxnes and van der Heijden, 2003; Van der Heijden and Moxnes, 2013) shows that a leader can reduce public bad provision; and Pevnitskaya and Ryvkin (2013) find that an environmental frame improves the outcome. The work most closely related to ours is Delaney and Jacobson (2014), which studies contributions to a public good when passive agents bear negative externalities so large that they outweigh the local benefits (so the project is overall anti-social), including a treatment that allows favor trading. They find that greater social

\footnotetext{
${ }^{2}$ Alternately, others suggest that some contributions are driven by confusion; examples include Andreoni (1995a), Ferraro et al. (2003), and Houser and Kurzban (2002).

${ }^{3}$ Shitovitz and Spiegel (2003) show that in general equilibrium, the Nash equilibrium outcome for provision of a public bad differs from that for a public good because provision of a public bad can be unbounded.

${ }^{4}$ The difference between positive and negative framing also relates to findings, like those in DeScioli et al. (2011), that anti-social acts of omission occur more frequently and receive less punishment than acts of commission.
} 
distance to injured parties increases public bad provision and that favor trading occurs among beneficiaries of this anti-social setting. Murray et al. (2015) approach a similar topic with a different game structure and also find anti-social favor trading emerging in a team production game. Malmendier and Schmidt (2012) also find that gift-giving can cause anti-social reciprocation and propose a model of endogenous formation of social reference groups. Our current study adds to this literature by examining favor trading in support of a public bad when the costs of provision are borne within the group.

The favor trading we study comprises reciprocal acts rooted in other-regarding preferences and those motivated by strategic self-interest ("intrinsic" and "instrumental" reciprocity, respectively, per Sobel, 2005). Intrinsic reciprocity (as laid out in theories like Cox et al., 2008; and Rabin, 1993) has been shown to drive pro-social behavior (e.g., Berg et al., 1995; Charness and Rabin, 2002; Cox, 2004; Fehr et al., 1993). Instrumental reciprocity has also been found to be important (e.g., List, 2006). Per the classifications of Cox and Deck (2005), our model does not allow negative reciprocity (spite) in the sense of punishment of a previous malefactor as studied in work like Abbink et al. (2000); all reciprocal acts in our model are positive in that they involve reward of a previous benefactor and withholding of that reward. ${ }^{5}$ Negative reciprocity can be pro-social when it is used to enforce cooperative norms. In contrast, we show that (positive) reciprocal acts can be socially harmful.

In public good games, reciprocal behavior has largely been studied in the form of conditional cooperation (Gächter, 2007). Information conditions and payoff asymmetries can provide additional leverage for reciprocity. Information alone may increase giving (e.g., Andreoni and Petrie, 2004; Sell and Wilson, 1991). But information can also enable reciprocity:

\footnotetext{
5 “Strong reciprocity" (Fehr et al., 2002) comprises both positive and negative reciprocity.
} 
you cannot reciprocate without knowing who has been kind to you (Wilson, 2008). ${ }^{6}$ This reciprocity may increase provision. Asymmetric payoffs can also act as levers for favor trading, although they have mostly been used to study responsiveness to returns to self and others (e.g., Goeree et al., 2002) or leadership (e.g., Brandts et al., 2007; Glöckner et al., 2011), sometimes in the spirit of Olson’s (1965) “privileged groups” (Reuben and Riedl, 2009). Other asymmetric return models study behavior when the project has different returns for people with no voice in project provision: "bystanders” in Engel and Rockenbach (2011), future generations in Sherstyuk et al. (2015), and “outsiders” in Delaney and Jacobson (2014). Isaac et al. (2013) study projects that are asymmetric (benefit some and hurt others), but give no opportunities for favor trading. Jacobson and Petrie (2014), in a design similar to our study, use asymmetric returns and information to let subjects trade favors in support of a public good. They show that favor trading occurs and other-regarding preference-based reciprocity boosts support of a pro-social common project. We ask whether this will also occur in support of an anti-social common project.

This study contributes to the literature by seeking evidence of reciprocal behavior in project provision when the project is anti-social. In a similar vein, Großer et al. (2013) use an influence-peddling game to show reciprocal behavior that subverts the majority's wish for redistribution. Delaney and Jacobson (2014) demonstrate a similar concept but in that study, the costs associated with the project are borne by agents outside the deciding group. In situations we study in this paper, all of the pain caused by project provision is borne by those who are deciding whether to support the project. Therefore, we study situations that involve significant sacrifice of own interest as well as the group's, rather than a sacrifice mainly of others' well-being, in pursuit

\footnotetext{
${ }^{6}$ Indirect or generalized reciprocity, as in Nowak and Sigmund (2005), needs no such information, but we are unable to identify this phenomenon in this study.
} 
of reciprocal rewards. The conditions of the current study are therefore perhaps the most extreme in which favor trading has been identified.

\section{Model}

We model a "Stakeholder Public Bad” game. Members of a group make repeated simultaneous individual decisions to contribute to a common pot. These contributions fund a public project with asymmetric returns: some group members benefit from provision while others are hurt, and the socially optimal level of provision is zero. One can interpret contributions as public bad provision or common pool resource appropriation.

Agents (indexed as i) belong to groups of size $N=4$. Group membership is fixed and the interaction continues for a finite number of periods. There are two roles, indexed by $r$. In each period $t$, one group member is exogenously assigned the role of Stakeholder (if Stakeholder $r_{t}=i$, so $r=S$ ) while the rest are Non-Stakeholders $(r=N S)$; we describe the roles below. The decision each agent must make in each period is, out of an endowment of $z=10$ tokens, how many tokens $g_{i t}$ to contribute to a common fund, with the rest of the endowment going into that agent's private fund. For each token an agent contributes to his private fund, he alone earns return $a>0$. Agent $i$ earns role-specific return $b_{r}$ for every token contributed by any group member to the common fund. Each agent also earns a role-specific baseline return $G_{r}$ from the "status quo" (no contributions) level of public project provision. ${ }^{7}$

The Stakeholder prefers the common project to the status quo: the Stakeholder return from the common fund is $b_{s}>a>0$, making this a privileged group (Olson, 1965). The

\footnotetext{
${ }^{7}$ This fixed status quo is similar to the "alternative public project” in Isaac et al. (2013). There, however, agents can contribute to this alternative and such contributions actually reduce provision of the main project.
} 
Stakeholder role rotates through some or all group members from period to period. ${ }^{8}$ Non-

Stakeholders prefer the status quo: their per-token return from the public fund is $b_{N S}<0<a$.

Agent $i$ 's payoff for period $t$ is given by equation 1 .

$$
\pi_{i t}=\left\{\begin{array}{l}
G_{S}+b_{S}\left(\sum_{j=1 \ldots N} g_{j t}\right)+a\left(z-g_{i t}\right) \quad \text { if Stakeholder } r_{t}=i \\
G_{N S}+b_{N S}\left(\sum_{j=1 \ldots N} g_{j t}\right)+a\left(z-g_{i t}\right) \text { if Stakeholder } r_{t} \neq i
\end{array}\right.
$$

The project is a public bad if the total return from a contributed token is negative. This happens if the total losses of Non-Stakeholders plus the opportunity cost of a token are larger than the gains of Stakeholders. Thus, the project is a public bad if $b_{S}+(N-1) b_{N S}<a$. In our implementation, the private fund payoff is $a=\$ 0.02$, the Group Fund payoff for Stakeholders is $b_{S}=\$ 0.10$, and the Group Fund payoff for Non-Stakeholders is $b_{N S}=-\$ 0.05$. This differs from Jacobson and Petrie (2014) because in that paper, the project is a public good $\left(b_{S}+(N-1) b_{N S}>a\right)$. It differs from Delaney and Jacobson (2014) because there the project hurts people outside the group, while here, it hurts the decision-makers themselves.

Group Fund base payment is $G_{S}=0$ for Stakeholders and $G_{N S}=\$ 2.00$ for NonStakeholders. This ensures that Non-Stakeholders can never earn a negative amount in a round; the Stakeholder base payment $G_{S}$ is zero because this concern does not exist for that role. ${ }^{9}$

In our Full Rotation treatment, each subject is Stakeholder twice and Non-Stakeholder six times. In our Two Stakeholder treatment, the Stakeholder role rotates through two of the four group members so they are each Stakeholder four times and Non-Stakeholder four times, and the

${ }^{8}$ A Stakeholder in a project that would be anti-social may be able to (in addition to not contributing) "bury" his project so no-one else can contribute. Our model represents situations in which a Stakeholder has no such power.

${ }^{9}$ This is payoff-identical to having an endowment for the treatment of $\$ 2$ times the number of rounds this subject will be Stakeholder. Of course, the framing of the endowment as role-specific may elicit different behavior. 
other group members are always Non-Stakeholder. The Stakeholder rotation and all contribution histories are public in our Public information condition but private in our Private condition.

\section{Theoretical Predictions}

If all agents are purely self-regarding money-maximizers and know others are the same, ${ }^{10}$ each role has a dominant corner strategy in the stage game of all treatments: each agent contributes fully to the common fund when he is Stakeholder and contributes nothing when NonStakeholder. Because there is a known end-period, they do not strategically cooperate because they expect unraveling. Therefore, the subgame perfect equilibrium of the finitely-repeated game is the same as the equilibrium of the stage game: group investment is 10 , the Stakeholder earns $\$ 1.00$, Non-Stakeholders each earn $\$ 1.70$, and total group earnings are $\$ 6.10$. The social optimum is zero contributions, so $\$ 0.20$ and $\$ 2.20$ and total group earnings are $\$ 6.80$. Group earnings are lowest (at \$4.00) if all agents contribute all tokens.

Could a subset of a group form a coalition for their mutual benefit? Only if colluding increases the joint payoff of coalition members. With our parameters, a two-person coalition wherein the Non-Stakeholder contributes when the other coalition member is Stakeholder increases joint payoff as compared to the simple self-interested prediction because the withinpair return to a token contributed $\left(b_{S}+b_{N S}\right)$ is greater than the opportunity cost $(a)$. There is no coalition enforcement mechanism, so such coalitions should fail with self-interested players unless they do incomplete backward induction. A coalition could also be maintained if agents have social preferences as discussed below so they trust each other to maintain collusion.

\footnotetext{
${ }^{10}$ Agents that are imperfectly maximizing would deviate away from these corner strategies: confusion would increase Non-Stakeholder contributions and decrease Stakeholder contributions. However, confusion could not create the appearance of favor trading.
} 
Other-regarding agents face a dilemma. Contribution helps one group member at others' expense and reduces efficiency. While efficiency-seeking, pure and impure altruism (Andreoni, 1989), conditional cooperation (Gächter, 2007), and indirect reciprocity (e.g., Nowak and Sigmund, 2005) could affect behavior, ${ }^{11}$ the main force of interest here is reciprocity. If agents are inequity-averse (e.g., Fehr and Schmidt, 1999), they could respond to the different baseline returns of Stakeholder and Non-Stakeholder. This should have no effect in the Full Rotation treatment since everyone plays both roles the same number of times, but in the Two Stakeholder treatment, inequity aversion could increase contributions in both roles.

Group members can use the rotating Stakeholder position to engage in reciprocity ${ }^{12}$ if they have information on each other's past giving. Reciprocal acts would primarily manifest as Non-Stakeholder contributions to reward the current Stakeholder for past Non-Stakeholder contributions. Imagine that first Adam is Stakeholder, then Beatrice, then Cynthia. In the first period, Beatrice contributes a lot and Cynthia contributes nothing. Adam behaves reciprocally if he contributes a lot when Beatrice is Stakeholder and little when Cynthia is Stakeholder. With reciprocal other-regarding preferences (intrinsic reciprocity), this is because Adam’s preferences for Beatrice’s and Cynthia’s payoffs are changed by their past acts. Reciprocity may instead be instrumental if an agent expects others to reward kind acts. With pure self-interest, common knowledge, and perfect rationality, instrumental reciprocity unravels. If agents are myopic, unraveling may be incomplete, yielding strategic contributions in early periods.

${ }^{11}$ Efficiency-seeking decreases all contributions. Pure and impure altruism reduce Stakeholder contributions; they reduce Non-Stakeholder contributions unless they privilege the current Stakeholder, in which case they increase them. Non-Stakeholders who conditionally cooperate increase contributions to cooperate with the Stakeholder or decrease them to cooperate with Non-Stakeholders. Indirect reciprocity could have similar effects.

${ }^{12}$ Contributions by Non-Stakeholders to benefit Stakeholders show positive reciprocity. The withholding of those "gifts" is not negative reciprocity, as discussed above. Contributions made to hurt Non-Stakeholders could show negative reciprocity, but they are not targeted at any individual so are poor tools for the purpose. Attempts at punishment by Non-Stakeholders are even less likely because the punisher (and bystanders) would be hurt as much as the intended recipient of the punishment. 
Like Non-Stakeholder contributions, Stakeholder contributions could be affected by reciprocity, but this is less likely. A Stakeholder who wishes to earn higher contributions in future Stakeholder stints or to reward kindness of past benefactors (which kindness may consist of higher Non-Stakeholder contributions when this subject was Stakeholder or lower Stakeholder contributions) may reduce his contributions since those contributions hurt his group members. However, since this does not target any particular person and benefits all group members, it is a weak tool for reciprocation. When only two people can be Stakeholder, however, the signal sent by this act may be strong enough to enable this channel of reciprocity.

Our treatments allow us to test hypotheses about reciprocity and coalition-forming. First, reciprocity requires that agents know one another's history of actions and schedule of Stakeholder timing. In our Public information condition, group members know one another's contribution history and roles in each period. In the Private condition, they know only their own role and history; they learn the individual amounts contributed in past periods but cannot associate them with any particular group member and do not know the timing of others' Stakeholder stints. ${ }^{13}$ Therefore, our null hypothesis is that contributions in each role do not differ between the Public and Private conditions. If reciprocity is an important motivator, we may reject this hypothesis because of increased Non-Stakeholder or decreased Stakeholder contributions in the Public condition. However, reciprocity need not change average levels of contributions because it could decrease kindness toward those perceived as unkind and increase kindness toward those perceived as kind. ${ }^{14}$ Therefore, our more important null hypothesis about reciprocity is that Non-Stakeholder contributions given by subject $i$ when subject $j$ is Stakeholder

\footnotetext{
${ }^{13}$ In the Private Two Stakeholder treatment, each potential Stakeholder always knows who the current Stakeholder is, but they do not know what that person has done in past rounds.

${ }^{14}$ One could argue that the right baseline for comparing Public condition contributions is "self-interested" behavior (zero contributions) rather than the positive contributions that may exist given other motives. However, theories such as Cox et al. (2008) allow reciprocity to exist against a background of other preferences and behaviors.
} 
will not differ based on $j$ 's past contributions when $i$ was Stakeholder. We will reject this if subjects reciprocate, i.e. if they discriminate between previously kind and unkind Stakeholders.

Second, two-player coalitions should be easier to form in our Two Stakeholder than our Full Rotation condition, where subjects have no way to identify a single partner. Since coalitions can increase Non-Stakeholder contributions or decrease Stakeholder contributions, our null hypothesis is that contributions in each role and tendency to reciprocate do not differ between the Full Rotation and Two Stakeholder treatments. If coalitions form, we will reject this hypothesis because of increased Non-Stakeholder and decreased Stakeholder contributions in the Two Stakeholder treatment, particularly in the Public condition. Further, these effects (increased NonStakeholder contributions, decreased Stakeholder contributions, and discrimination based on past behavior) should hold for potential Stakeholders but not those who will never be Stakeholder.

\section{Experiment}

We implement the Stakeholder Public Bad game in a laboratory experiment based on a linear public bad game with rotating asymmetric payoffs, using the model and parameters outlined above. We use four treatments crossing the Public and Private information conditions with the Full Rotation and Two Stakeholder role configurations.

In the Public condition, each subject is assigned a letter code. Subjects see a table in which the timing of the Stakeholder position is reported and each group member's contribution history is shown. In the Private condition, subjects' contributions to the common project (called the Group Fund) are reported in a disaggregated list (it has been noted, e.g., Sell and Wilson, 1991, that disaggregated reporting affects giving). Because contributions are disaggregated, norms may be established and subjects may follow one another. However, because contributions 
are listed in a random order that is reshuffled each round reputations cannot be established and Stakeholder timing is private information, so targeted reciprocity is impossible.

In the Full Rotation configuration, the Stakeholder position rotates through all four group members so each is Stakeholder twice in eight rounds. In the Two Stakeholder treatment, only two of the four group members will be Stakeholder. This focuses each potential Stakeholder's favor trading efforts into a small circle in which reciprocity can increase joint payoffs.

The experimental procedure is outlined in Figure 1. The subject interface is computerized using software written in z-Tree (Fischbacher, 2007). Subjects enter the lab and are given general instructions. ${ }^{15}$ They are told that they will make decisions in two sets of eight rounds with two different groups and that they will then make one unrelated decision, but are not told the exact nature of the decisions they will make in each treatment until directly before the treatment begins. The design is both within and across subject—each subject participates in both the Public and Private information conditions, but we only use one information condition for each subject as discussed below; also, each subject participates in either the Full Rotation or Two Stakeholder role configuration. The final task is a risk preference elicitation in the style of Holt and Laury (2002). The protocol is double anonymous: subjects cannot identify which subjects are in their group, and the experimenters cannot identify which subject made which decisions. The payment procedure is described in the general instructions so subjects understand throughout all rounds that their decisions will be anonymous.

\footnotetext{
${ }^{15}$ Instructions are available on the corresponding author's website.
} 


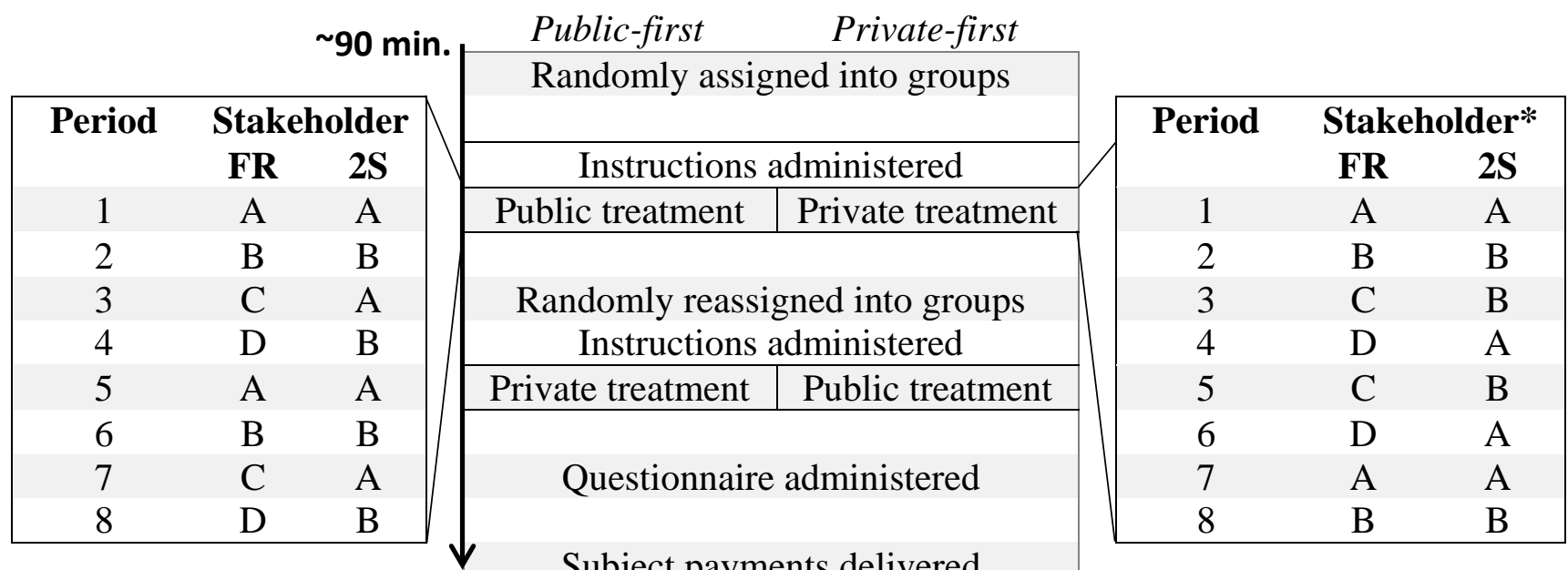

*The Stakeholder position in the Private treatment follows this pattern, but letter codes are not revealed to subjects in this treatment. FR is the Full Rotation treatment; 2S is the Two Stakeholder treatment. Half of the sessions began with the Public treatment first, while half began with the Private treatment first.

Figure 1. Experiment design.

The first treatment begins with instructions (read aloud) for that treatment. The software randomly assigns subjects into four-person groups. The subjects then play through all of the rounds of the treatment. After the first treatment, subjects are randomly assigned into new fourperson groups. The second treatment features the complementary information condition and proceeds in the same way, with treatment-specific instructions read first. After both treatments are complete, subjects get instructions for and perform the risk task. Finally, subjects complete a questionnaire that does not ask uniquely identifying information. After the questionnaire, each subject collects payment anonymously from a mailbox matching his private ID number with noone watching. Each subject's total earnings are the sum of his earnings in each treatment, which in turn are the sum of his earnings in each round, plus his earnings from the risk task.

The experiment was run at the Experimental Economics Center (ExCEN) at Georgia State University in March 2010 and October 2014 in eight 20-subject sessions. All subjects played two eight-round treatments, one in a Public and one in a Private information condition. Half of the sessions ran the Public, and half the Private, treatment first. 


\section{Results}

We report results of individual-level analysis using within- and across-subject tests as appropriate. We find order effects, so all analysis only uses data from subjects' first treatment. ${ }^{16}$

\section{Summary of Data}

Of the 160 subjects, 88 (55\%) were female and the average age was 20.08. Sessions lasted about 90 minutes and average earnings were \$23.38 (standard deviation \$2.07). ${ }^{17}$

Subjects seemed to understand the public bad nature of the game. Nearly no confusion with the game was reported in the post-experiment questionnaire. ${ }^{18}$ Answers to a question about what they thought the experimenters would learn included: "People knowing how other vote, sway their decision on how they vote" and "That most people will look out for themselves first, before they would others.” When asked to describe the difference between the Group and Personal Funds, one subject said, "Peronsal [sic]: Own benefit, Group: Helps individuals but hurts the whole."

Figure 2 shows the path of contribution decisions across the rounds of each treatment. Stakeholder decisions in all treatments are close to the endowment, which is consistent with the selfish dominant strategy of full contribution by Stakeholders, but they are somewhat lower in the Two Stakeholder treatments. Recall that all contributions are socially costly because of the harm they cause to Non-Stakeholders. Non-Stakeholder contributions are low but positive in all

${ }^{16}$ The order effects are that Non-Stakeholder contributions are lower in Private if Public is first (9.20\% of endowment) than if Private is first $(20.61 \%$, Wilcoxon rank-sum $p<0.001)$ and Stakeholder contributions are lower in Public if Public is first (89.71\%) than if Private is first (95.75\%, Wilcoxon rank-sum $p=0.001)$. Results become stronger if the full data set is used: for example, in Full Rotation, Stakeholder contributions are significantly greater in Public (95.44\%) than in Private (92.44\%) $(p=0.038)$ and the Table 3 reciprocity test for Public Two Stakeholder is significant $(p=0.055)$.

${ }^{17}$ Twenty-seven of the 160 (16.88\%) subjects incorrectly answered a comprehension question on the questionnaire. The results we report include their data, but all results are robust to their exclusion except for a slight loss in power, and some results become stronger. People who answered this question incorrectly give more as NonStakeholder than those who don't (Wilcoxon rank-sum $p=0.002$ for Private, $p<0.001$ for Public).

${ }^{18}$ By far the most common exception was that some subjects found the risk elicitation confusing. 
rounds. Non-Stakeholder contributions show the downward trend usually seen in public goods games, even though this investment is actually a public bad. In the Two Stakeholder treatment, Stakeholder contributions show an upward trend, which is a decrease in cooperation over time. 


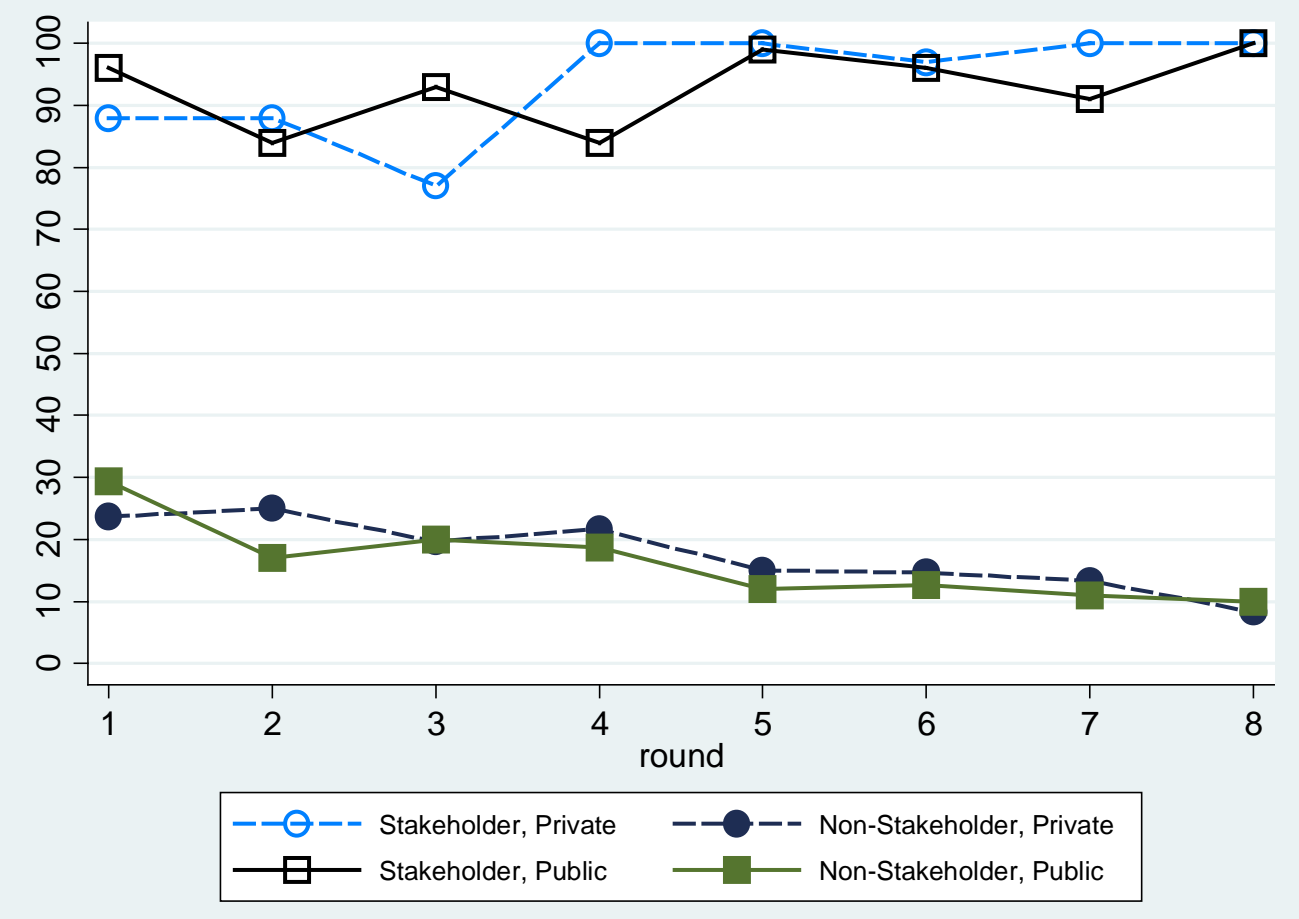

Panel A: Full Rotation Treatment

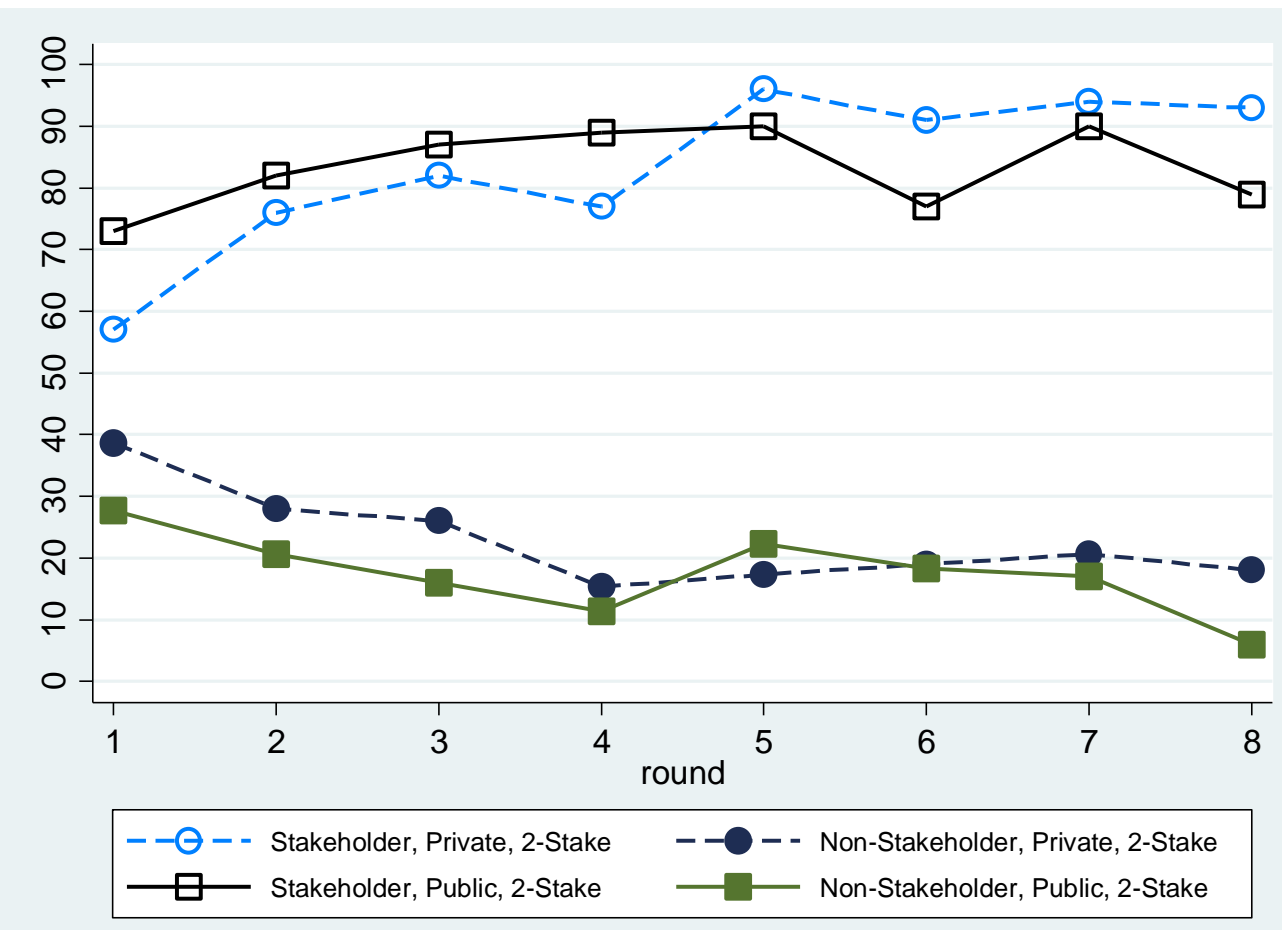

Panel B: Two Stakeholder Treatment

Figure 2: Contributions across rounds by role and treatment (in percent of endowment) 
Table 1 summarizes contribution choices across rounds. Most people perfectly follow the selfish dominant strategy when they are Stakeholder, though less so in the Two Stakeholder configuration, but most do not fully follow the selfish dominant strategy as Non-Stakeholders.

Table 1: Distribution of contribution amounts by treatment and role

\begin{tabular}{|c|c|c|c|c|}
\hline \multirow{2}{*}{ FULL ROTATION } & \multicolumn{2}{|c|}{ Non-Stakeholder } & \multicolumn{2}{|c|}{ Stakeholder } \\
\hline & Private & Public & Private & Public \\
\hline Gave $0 \%$ of endowment $^{\mathrm{a}}$ & $161(67.08 \%)$ & 140 (58.33\%) & $3(3.75 \%)$ & $2(2.5 \%)$ \\
\hline Gave intermediate amount $^{\mathrm{a}}$ & $60(25 \%)$ & $86(35.83 \%)$ & $8(10 \%)$ & $12(15 \%)$ \\
\hline Gave $100 \%$ of endowment ${ }^{a}$ & $19(7.92 \%)$ & $14(5.83 \%)$ & $69(86.25 \%)$ & $66(82.5 \%)$ \\
\hline Median contribution & 0 & 0 & Endowment & Endowment \\
\hline $\begin{array}{l}\text { Subjects who always follow } \\
\text { selfish dominant strategy }\end{array}$ & $13(32.5 \%)$ & $14(35 \%)$ & $29(72.5 \%)$ & 27 (67.5\%) \\
\hline Number of contributions & 240 & 240 & 80 & 80 \\
\hline Number of subjects & 40 & 40 & 40 & 40 \\
\hline \multirow{2}{*}{ TWO STAKEHOLDER } & \multicolumn{2}{|c|}{ Non-Stakeholder } & \multicolumn{2}{|c|}{ Stakeholder } \\
\hline & Private & Public & Private & Public \\
\hline Gave $0 \%$ of endowment ${ }^{\mathrm{a}}$ & $125(52.08 \%)$ & $140(58.33 \%)$ & $5(6.25 \%)$ & $1(1.25 \%)$ \\
\hline Gave intermediate amount $^{\mathrm{a}}$ & $99(41.25 \%)$ & $91(37.92 \%)$ & 27 (33.75\%) & $32(40 \%)$ \\
\hline Gave $100 \%$ of endowment ${ }^{a}$ & $16(6.67 \%)$ & $9(3.75 \%)$ & $48(60 \%)$ & $47(58.75 \%)$ \\
\hline Median contribution & 0 & 0 & Endowment & Endowment \\
\hline $\begin{array}{l}\text { Subjects who always follow } \\
\text { selfish dominant strategy }\end{array}$ & $10(25 \%)$ & $12(30 \%)$ & $7(35 \%)$ & $7(35 \%)$ \\
\hline Number of contributions & 240 & 240 & 80 & 80 \\
\hline Number of subjects & 40 & 40 & 20 & 20 \\
\hline
\end{tabular}

Testing for Reciprocity and Coalitions in Contribution Levels

We test some of our hypotheses by comparing mean contributions by role and treatment, as shown in Table 2. However, we present the strongest tests of reciprocity (discrimination in Non-Stakeholder contribution based on current Stakeholder's past actions) in the next section. 
Table 2: Mean contributions by role and treatment (in percent of endowment)

\begin{tabular}{|c|c|c|c|c|c|c|}
\hline $\begin{array}{l}\text { Panel A: NON- } \\
\text { STAKEHOLDER }\end{array}$ & $\begin{array}{c}\text { Full } \\
\text { Rotation }\end{array}$ & $\begin{array}{c}\text { Two } \\
\text { Stakeholder }\end{array}$ & $\begin{array}{c}\text { Full \& Two } \\
\text { Stakeholder } \\
\text { Different? }\end{array}$ & $\begin{array}{c}\text { Two } \\
\text { Stakeholder } \\
\text { Potential } \\
\text { Stakeholder }\end{array}$ & $\begin{array}{c}\text { Two } \\
\text { Stakeholder } \\
\text { Never } \\
\text { Stakeholder }\end{array}$ & $\begin{array}{c}\text { Potential- \& } \\
\text { Never- } \\
\text { Stakeholder } \\
\text { Different? }\end{array}$ \\
\hline Private & $\begin{array}{c}17.67 \\
(24.58)\end{array}$ & $\begin{array}{c}23.56 \\
(24.70)\end{array}$ & 0.140 & $\begin{array}{c}12.38 \\
(10.79)\end{array}$ & $\begin{array}{c}34.75 \\
(29.53)\end{array}$ & 0.013 \\
\hline Public & $\begin{array}{c}16.33 \\
(21.79)\end{array}$ & $\begin{array}{c}18.61 \\
(18.49)\end{array}$ & 0.381 & $\begin{array}{c}21.56 \\
(16.92)\end{array}$ & $\begin{array}{c}15.67 \\
(19.94)\end{array}$ & 0.217 \\
\hline $\begin{array}{l}N \text { per cell } \\
\text { Private \& Public } \\
\text { Different? }\end{array}$ & $\begin{array}{c}40 \\
0.992\end{array}$ & $\begin{array}{c}40 \\
0.453\end{array}$ & & $\begin{array}{c}20 \\
0.093\end{array}$ & $\begin{array}{c}20 \\
0.027\end{array}$ & \\
\hline $\begin{array}{c}\text { Panel B: } \\
\text { STAKEHOLDER }\end{array}$ & $\begin{array}{c}\text { Full } \\
\text { Rotation }\end{array}$ & $\begin{array}{c}\text { Two } \\
\text { Stakeholder }\end{array}$ & $\begin{array}{c}\text { Full \& Two } \\
\text { Stake } \\
\text { Different? }\end{array}$ & & & \\
\hline Private & $\begin{array}{c}93.75 \\
(13.95)\end{array}$ & $\begin{array}{c}83.25 \\
(19.50)\end{array}$ & 0.006 & & & \\
\hline Public & $\begin{array}{c}92.88 \\
(15.34) \\
\end{array}$ & $\begin{array}{c}83.38 \\
(19.27) \\
\end{array}$ & 0.009 & & & \\
\hline $\begin{array}{l}N \text { per cell } \\
\text { Private \& Public } \\
\text { Different? }\end{array}$ & $\begin{array}{c}40 \\
0.682\end{array}$ & $\begin{array}{c}20 \\
0.945\end{array}$ & & & & \\
\hline
\end{tabular}

Amounts given in percent of endowment. Standard deviations in parentheses. "Different” columns and rows report Wilcoxon rank-sum test $p$-values.

Are mean contribution levels different between Public and Private treatments? Not in the Full Rotation treatment, and not in the aggregate data from the Two Stakeholder treatment. Total group contributions also do not differ between Public and Private for Full Rotation (35.47\% versus $36.69 \%$ of total group endowment, Wilcoxon rank-sum test $p=0.449$ ) or Two Stakeholder (33.91\% versus 37.97, $p=0.705)$ conditions, nor between Full Rotation and Two Stakeholder treatments for Public $(p=0.650)$ or Private $(p=0.970)$ information conditions. However, as hypothesized, Non-Stakeholder contributions by potential Stakeholders are higher in the Public than the Private condition of the Two Stakeholder treatment $(p=0.093)$. This shows evidence of reciprocal giving and supports the hypothesis that coalitions are important. Surprisingly, this pattern in potential Stakeholder giving is offset by a decrease in contributions by Non-Stakeholders who will never be Stakeholder from the Private to the Public treatment. 
Finally, the data show reduced Stakeholder contributions in the Two Stakeholder treatments as compared to the Full Rotation treatment. This is further evidence that favor trading is enabled by coalition formation.

\section{Direct Tests of Reciprocal Giving}

As discussed when we presented our model, reciprocal giving need not increase average contributions, so a proper test of the hypothesis of reciprocal giving must see whether subjects' current contributions seem to return a "favor" done by another subject. We will start by focusing on reciprocity in Non-Stakeholder contributions, using non-parametric tests and regressions, and return later in this section to discuss reciprocity in Stakeholder contributions. ${ }^{19}$ We cannot distinguish between intrinsic and instrumental reciprocity because favor trading may be driven by strategic self-interest. ${ }^{20}$ Our tests will simply determine whether a subject discriminates between other subjects based on those other subjects' past behavior. Other motives can change the level of contributions, but only reciprocal giving can create such a discriminatory pattern.

To run non-parametric tests of Non-Stakeholder reciprocity, we classify the Stakeholder in each round as generous or ungenerous with regard to each Non-Stakeholder. We do this by calculating the current Stakeholder's average contribution in past rounds in which this (currently Non-Stakeholder) subject was Stakeholder. If the current Stakeholder gave more than half of his endowment on average to this subject, we classify him as generous with regard to this subject; if

\footnotetext{
${ }^{19}$ Although reciprocity can manifest itself in other ways (e.g. a Non-Stakeholder increasing contributions to hurt another Non-Stakeholder), these do not target an individual and are thus more like conditional cooperation. Further, we do not have the power to test for most of these. The exception is that in the Two Stakeholder treatment we look for reciprocity in Stakeholder contributions as discussed in Table 4. The patterns that would arise from other forms of reciprocity would not confound the tests of reciprocity we perform in this section.

${ }^{20}$ Jacobson and Petrie (2014) find evidence of intrinsic reciprocity in late-period cooperation (after a subject's last Stakeholder stint, so that rewards from strategic cooperation are low). In our study, groups are smaller and there are fewer rounds as compared to that study, so there is not sufficient power to perform such a test.
} 
not, we classify him as ungenerous. ${ }^{21}$ We perform a within-subject comparison of each subject's average Non-Stakeholder contribution when facing a previously-generous Stakeholder and his average Non-Stakeholder contribution when facing a previously-ungenerous Stakeholder.

Table 3 shows average Non-Stakeholder contributions by Stakeholder generosity for the Private and Public treatments. Since targeted reciprocity is impossible in the Private treatment, we do not expect a difference between these values for that treatment, and our data indeed show no significant difference. However, in the Public treatment, in which subjects have the information they need to discriminate in this way, Non-Stakeholders reciprocate significantly in the Full Rotation condition: they contribute more when the current Stakeholder was previously generous than when he was previously ungenerous. The within-subject difference is significant even though the sample size is greatly reduced. ${ }^{22}$ The same trend appears in the Two Stakeholder configuration, but, with a smaller sample size, it is not significant there. The difference in this discrimination across the Private and Public treatments is not significant (Wilcoxon rank-sum $p$ $=0.241$ for Full Rotation, $p=0.826$ for Two Stakeholder).

Table 3: Evidence of reciprocal contributions (contributions in percent of endowment)

\begin{tabular}{lcccc} 
& \multicolumn{2}{c}{ Full Rotation } & \multicolumn{2}{c}{ Two Stakeholder } \\
& Private & Public & Private & Public \\
\hline Stakeholder extracted $>50 \%$ when I was & 25.00 & 29.32 & 22.00 & 30.42 \\
$\quad$ Stakeholder in past & $(34.76)$ & $(32.24)$ & $(22.80)$ & $(27.93)$ \\
Stakeholder extracted $\leq 50 \%$ when I was & 19.23 & 9.06 & 15.50 & 17.29 \\
$\quad$ Stakeholder in past & $(30.37)$ & $(10.68)$ & $(13.62)$ & $(9.46)$ \\
\hline$N \quad$ Wilcoxon signed-rank test $p$-value & 13 & 11 & 5 & 8 \\
W & 0.420 & 0.058 & 0.494 & 0.182 \\
\hline
\end{tabular}

Amounts given in percent of endowment. $N$ is less than the number of subjects in each treatment because subjects who did not face both "generous" and "ungenerous" Stakeholder were dropped. Standard deviations in parentheses.

${ }^{21}$ Results hold for alternative specifications (30\% to $90 \%$ of endowment) of the threshold for generosity.

${ }^{22}$ Most people do not face both a previously-kind and a previously-unkind Stakeholder. Each subject has only 3-6 rounds as Non-Stakeholder after his first Stakeholder stint. Since most Non-Stakeholder contributions are zero, few subjects face both types of Stakeholders after their first Stakeholder stint in this small number of rounds. 
Comparing values across columns of Table 3, we find no significant difference between what subjects give to a previously-generous Stakeholder in the Private as compared to the Public treatment ( $p=0.383$ for Full Rotation, $p=0.652$ for Two Stakeholder) and what they give to a previously-ungenerous Stakeholder in the Private as compared to the Public treatment $(p=0.787$ for Full Rotation, although in Two Stakeholder with $p=0.027$ Public is greater than Private). Therefore, we cannot say whether reciprocity results from greater kindness to past benefactors, reduced kindness to those who previously refused to be kind, or both. However, the magnitudes in Table 3 suggest that in the Full Rotation treatment, reciprocity may act by decreasing contributions to previously-ungenerous Stakeholders while in the Two Stakeholder treatment, it may act by increasing contributions to previously-generous Stakeholders.

To test for reciprocal giving in the full data set, we regress contributions on past generosity to this subject. We discuss first Non-Stakeholder and then Stakeholder contributions. We define $g_{i t}^{N S}$ as subject $i$ 's Non-Stakeholder contributions in period $t$. We wish to see the relationship between $g_{i t}^{N S}$ and cumulative average "favor" contributions $\left(\bar{f}_{i j t}\right)$ : contributions by current (round $t$ ) Stakeholder $j$ in previous periods when subject $i$ was Stakeholder. We define Public treatment indicator variable $d_{p}$, and we interact it with $\bar{f}_{i j t}$. To limit the effects of the cross-correlations that may cause endogeneity, we also control for the cumulative average NonStakeholder contribution of other subjects in this group $\left(\bar{g}_{i t}^{N S}\right)$. We also control for a time trend $t$ (the period number). We include a dummy $d_{2}$ for the Two Stakeholder treatment. (Only data from the subjects in the Two Stakeholder treatment who rotated into the Stakeholder position are 
in this regression since never-Stakeholders cannot receive favor contributions.) We estimate a full interaction model, and we use individual random effects. ${ }^{23}$

We perform GLS and Tobit regressions of this model. Since the design features interacted treatments, the net effect of each variable in each treatment is generally seen in the sum of regression coefficients. Therefore, rather than presenting raw regression results, we present summed coefficients and significance levels in Table 4. Specification 1 shows results for a GLS regression and specification 2 shows marginal effects from a Tobit regression.

${ }^{23}$ Particularly in the Two Stakeholder treatment, a within-treatment test of reciprocal giving is less sensible than an across-subject test. In the Two Stakeholder treatment, each potential Stakeholder only faces one other potential Stakeholder so a within subject test looks at how a person responds to fluctuation within one person's contributions. The main results hold for the Full Rotation treatment using fixed effects. 
Table 4: Effects by treatment from regression interaction terms

\begin{tabular}{|c|c|c|c|c|}
\hline & $\begin{array}{c}\text { 1: Non- } \\
\text { Stakeholder } \\
\text { (GLS) }\end{array}$ & $\begin{array}{c}\text { 2: Non- } \\
\text { Stakeholder } \\
\text { (Tobit) }\end{array}$ & $\begin{array}{c}\text { 3: } \\
\text { Stakeholder } \\
\text { (GLS) }\end{array}$ & $\begin{array}{c}\text { 4: } \\
\text { Stakeholder } \\
\text { (Tobit) }\end{array}$ \\
\hline $\begin{array}{l}\text { Two Stakeholder treatment (as compared to Full } \\
\text { Rotation) }\end{array}$ & -11.11 & -12.19 & -9.76 & -2.95 \\
\hline \multicolumn{5}{|l|}{ Public treatment } \\
\hline Effect in Full Rotation & -20.89 & -58.54 & -1.03 & 10.37 \\
\hline Effect in Two Stakeholder & 40.87 & 71.04 & 55.84 & 129.86 \\
\hline \multicolumn{5}{|l|}{$\begin{array}{l}\text { Stakeholder average past contributions to me } \\
\text { (percent of endowment) }\end{array}$} \\
\hline Effect in Private Full Rotation & 0.10 & $0.31 * *$ & & \\
\hline Effect in Public Full Rotation & $0.33^{* * *}$ & $0.55 * * *$ & & \\
\hline Effect in Private Two Stakeholder & -0.07 & -0.26 & & \\
\hline Effect in Public Two Stakeholder & $0.37 * *$ & 0.59 & & \\
\hline \multicolumn{5}{|l|}{$\begin{array}{l}\text { Effect of Publicity on effect of Stakeholder average } \\
\text { past contributions to me (percent of endowment) }\end{array}$} \\
\hline Effect in Full Rotation & $0.23 *$ & 0.25 & & \\
\hline Effect in Two Stakeholder & $0.44^{*}$ & 0.85 & & \\
\hline \multicolumn{5}{|l|}{$\begin{array}{l}\text { Average past Non-Stakeholder contributions } \\
\text { (excluding self) (percent of endowment) }\end{array}$} \\
\hline Effect in Private Full Rotation & 0.09 & 0.17 & 0.20 & 1.05 \\
\hline Effect in Public Full Rotation & $0.32 *$ & $1.07 * *$ & 0.10 & 0.51 \\
\hline Effect in Private Two Stakeholder & -0.01 & -0.14 & $0.31^{*}$ & 1.10 \\
\hline Effect in Public Two Stakeholder & -0.54 & -0.88 & $-0.62 *$ & -1.08 \\
\hline \multicolumn{5}{|l|}{$\begin{array}{l}\text { Average past Stakeholder contributions (excluding } \\
\text { self) (percent of endowment) }\end{array}$} \\
\hline Effect in Private Full Rotation & 0.03 & 0.01 & 0.13 & 0.21 \\
\hline Effect in Public Full Rotation & 0.08 & 0.24 & 0.18 & 0.44 \\
\hline Effect in Private Two Stakeholder & $0.16^{* *}$ & 0.39 & 0.05 & -0.20 \\
\hline Effect in Public Two Stakeholder & 0.07 & 0.02 & 0.03 & 0.03 \\
\hline Period & $-2.49 * *$ & $-6.32 * *$ & $2.78 * *$ & $23.27 * * *$ \\
\hline Number of observations & 460 & 460 & 280 & 280 \\
\hline Number of subjects & 120 & 120 & 120 & 120 \\
\hline Cluster & Subject & No & Subject & No \\
\hline Wald chi-squared & 99.16 & 56.61 & 29.49 & 25.35 \\
\hline$R^{2}$ (overall) / Log likelihood & 0.184 & -949.444 & 0.117 & -422.310 \\
\hline
\end{tabular}

There are some differences between GLS and Tobit results, but the general results are as

follows. First, this more complete analysis also supports the hypothesis that subjects behave

reciprocally when they have the information to do so. The net coefficient on $\bar{f}_{i j t}$ (the "favor"

contribution by the current Stakeholder) is generally positive and significant in the Public 
treatments but not significant in the Private treatments. ${ }^{24}$ In the GLS specification, the difference in favor trading between the Public and Private treatments of both Full Rotation and Two Stakeholder is significant and positive, which further supports the hypothesis of reciprocity. The results are generally robust to the exclusion of the last period. ${ }^{25}$

We now turn to Stakeholder contributions, which can only be used for targeted reciprocity in the Two Stakeholder configuration. In specifications 3 and 4 of Table 4, we regress Stakeholder contribution on round covariates. While the effect does not remain significant in the Tobit specification, the GLS specification indicates that in the Two Stakeholder setting only, current Stakeholder contributions increase with others’ Non-Stakeholder contributions when histories are Private but decrease in them when they are Public. Though this result is sensitive to specification, ${ }^{26}$ it suggests that favor trading is also taking the pro-social form of decreased Stakeholder contributions.

\section{Discussion}

Our results, though new, are congruent with existing literature. In Jacobson and Petrie (2014) where the common fund is a public good instead of a public bad, Stakeholders give slightly more (95-97\% of endowment) than they do here and Non-Stakeholders give much more (33-38\%) than they do here, and both roles show trends similar to the trends shown here. In the favor trading treatment of Delaney and Jacobson (2014), in which all group members get

\footnotetext{
${ }^{24}$ In the Tobit regression, favor trading appears to be significant in the Private Full Rotation treatment. From examining the data, it seems that this spurious correlation occurs because Non-Stakeholders generally have low last-period contributions and some Stakeholders also steadily reduce contributions across rounds.

${ }^{25}$ When the last period is excluded, power is greatly reduced, particularly in the Stakeholder regressions. We see these differences: in Specification 2, current Stakeholder past kindness becomes significant in Public Full Rotation; in Specification 3, the tests of summed coefficients for past Non-Stakeholder contributions in Two Stakeholder Private and Public cease to be significant.

${ }^{26}$ For both the Private and Public treatments, the coefficients for Tobit are larger than those for GLS but not significant because of increased standard errors. The Tobit specification coefficient for the Private treatment is just past conventional significance, with $p=0.143$, while that for Public becomes significantly noisier so $p=0.402$.
} 
positive returns but two people outside the group get large negative returns to the common fund, subjects give much more as Non-Stakeholders (32-36\%) than they do here and as Stakeholders give (83-85\% of endowment) about what they give here in the Two Stakeholder treatment, again showing a similar pattern across rounds. Reciprocal giving occurs in this "public bad” setting just as it does in a public good setting as shown in Jacobson and Petrie (2014). In fact, while a Non-Stakeholder favor contribution of one percent of endowment generates 0.33 to 0.59 more contributions in percent of endowment when the person becomes Stakeholder in the current study, in Jacobson and Petrie (2014) the same relative size of contribution generates only 0.2 to 0.24 percent of endowment in return contributions. Of course, there are fundamental differences in game structure between the current game and the existing literature, and future research can study how subjects react to each differing element of institutional structure.

Does it pay to trade favors in this game? For example, is the sacrifice of contributing to the Group Fund worthwhile for a Non-Stakeholder? Using the GLS coefficients, for a one percent of endowment (0.1 token) contribution the current Stakeholder has given in previous rounds, Non-Stakeholders in the Public treatment contribute an additional 0.33 percent of endowment ( 0.033 tokens), or 0.33 tokens per token contributed. The net private cost of contributing a token when Non-Stakeholder is -7 cents, while Stakeholders earn 10 cents from each token donated by other subjects. The reciprocity-fueled net return to a token contributed by a Non-Stakeholder is thus $(10 \times 0.33)-7=3.3-7=-3.7$ cents. Even at the upper bound of the confidence interval for any reasonable confidence level, future reciprocation does not render Non-Stakeholder contributions profitable on average. By the same logic, reciprocity in any other treatment or specification is similarly unprofitable. Giving a favor is also unprofitable in 
Jacobson and Petrie (2014), but it is profitable in Delaney and Jacobson (2014), where giving is also anti-social but costs are borne by people outside the group of decision-makers.

Offering a favor in this setting, either by giving a Non-Stakeholder contribution or by reducing contributions when Stakeholder, is therefore extremely risky. Our subjects performed a risk preference elicitation in the style of Holt and Laury (2002), and we report contributions by risk aversion levels in Table 5. Less risk averse subjects give more as Non-Stakeholders and less as Stakeholders in data pooled across treatments, though this is only statistically significant for Non-Stakeholders in the Private treatment and for Stakeholders in the Public treatment. ${ }^{27}$ This is consistent with subjects viewing these favors as risky assets in which they may choose to invest.

Table 5: Risk preferences and contributions

\begin{tabular}{lcccc} 
& \multicolumn{2}{c}{ Non-Stakeholder } & \multicolumn{2}{c}{ Stakeholder } \\
& Private & Public & Private & Public \\
\hline Less risk averse & 26.86 & 19.21 & 87.26 & 83.80 \\
& $(27.80)$ & $(22.10)$ & $(18.74)$ & $(20.05)$ \\
More risk averse & $N=32$ & $N=29$ & $N=21$ & $N=23$ \\
& 16.45 & 16.49 & 91.86 & 93.38 \\
& $(21.64)$ & $(19.05)$ & $(15.37)$ & $(14.24)$ \\
& $N=48$ & $N=51$ & $N=39$ & $N=37$ \\
\hline Wilcoxon rank-sum $p$-value & 0.079 & 0.575 & 0.331 & 0.033 \\
\hline \multicolumn{2}{c}{ Amounts given in percent of endowment. Standard deviations in parentheses. }
\end{tabular}

\section{Conclusion}

Trust and reciprocity, some argue, may act as the "social glue” (e.g., Karlan, 2005) that enables the social and commercial intercourse on which economies are built. Even negative reciprocity has been shown to play a pro-social role (e.g., Abbink et al., 2000). In this paper, we examine reciprocal behavior in the provision of a public bad. We model a sequence of inefficient

\footnotetext{
${ }^{27}$ When Full Rotation and Two Stakeholder data are studied separately, the same patterns emerge in all cases except for Stakeholder contributions in the Public Full Rotation condition.
} 
projects, each of which is privately desirable to a booster within the group. Natural analogies include political logrolling or influence peddling.

We find that when subjects benefit directly from a public bad, they contribute nearly fully. Further, when they have the information that enables reciprocation, people use contribution choices to trade favors, although provision does not increase. When we make it easier for people to form a coalition, favor-trading becomes stronger but also takes the added pro-social form of reduced provision by the project booster. However, since favor trading does occur, in other settings (with other parameters or a different population) public bad provision could increase or decrease as a result of this phenomenon.

Our results show that reciprocity, and the information and institutional structures that enable it, can cause social harm. This is congruent with Malmendier and Schmidt (2012) and Murray et al. (2015), who find welfare-reducing favor trading in other settings. However, the role of information in enabling collusion has received attention at least since Stigler (1964). We also echo the findings of Cohen and Malloy (2014), who find that the influence on US Senators' votes of favor trading within peer networks is $57 \%$ the size of the influence of the interests of a Senator's own state. Our results support the argument of Ackerman and Ayres (2002) that all campaign contributions should be anonymous to render political favor trading impossible.

Other institutional features may amplify or diminish the kind of effects we observe. Indeed, Cohen and Malloy (2014) find that the favor trading practiced by lawmakers with members of their social networks is responsive to the costs of providing those favors and the benefits those favors will confer. A longer-lived interaction may increase the benefits to reciprocity and therefore engender more favor trading when public information is available. If agents can communicate with each other, especially if those messages are hidden from group 
members, that might further enhance favor trading and particularly anti-social favor trading within a coalition. If each person's “pet project” (with negative externalities to the group) is continually ongoing so that people have continual opportunities to support each other and to reciprocate, this might also strengthen favor trading. If parameters were different, favor trading may increase or decrease, with either anti-social or pro-social results—-for example, if pet projects were more socially costly, Non-Stakeholder support would be more infrequent but therefore might send a stronger signal as a tool in favor trading; but in the same setting we might see more favor trading through Stakeholder's reduced support of his or her own pet project.

A vast literature has shown that altruism and pro-social reciprocity are real and powerful. In our study, however, we find that individuals may attempt to harness reciprocity and information as a force for the good of the few but against the good of the many. 


\section{References}

Abbink, K., Irlenbusch, B., Renner, E., 2000. The moonlighting game: An experimental study on reciprocity and retribution. Journal of Economic Behavior \& Organization 42, 265-277.

Ackerman, B.A., Ayres, I., 2002. Voting with dollars: a new paradigm for campaign finance. Yale Univ Pr.

Andreoni, J., 1989. Giving with impure altruism: Applications to charity and Ricardian equivalence. The Journal of Political Economy 97, 1447.

Andreoni, J., 1995a. Cooperation in Public-Goods Experiments: Kindness or Confusion?

American Economic Review 85, 891-904.

Andreoni, J., 1995b. Warm-Glow versus Cold-Prickle: The Effects of Positive and Negative Framing on Cooperation in Experiments. Quarterly Journal of Economics 110, 1-21.

Andreoni, J., Petrie, R., 2004. Public goods experiments without confidentiality: A glimpse into fund-raising. Journal of Public Economics 88, 1605-1623.

Barr, A., Serra, D., 2009. The effects of externalities and framing on bribery in a petty corruption experiment. Experimental Economics 12, 488-503.

Barr, A., Serra, D., 2010. Corruption and culture: An experimental analysis. Journal of Public Economics 94, 862-869.

Berg, J., Dickhaut, J.W., McCabe, K.A., 1995. Trust, Reciprocity, and Social History. Games and Economic Behavior 10, 122-142.

Brandts, J., Cooper, D.J., Fatas, E., 2007. Leadership and Overcoming Coordination Failure with Asymmetric Costs. Experimental Economics 10, 269-284.

Charness, G., Rabin, M., 2002. Understanding Social Preferences with Simple Tests. Quarterly Journal of Economics 117, 817-869.

Chaudhuri, A., 2011. Sustaining Cooperation in Laboratory Public Goods Experiments: A

Selective Survey of the Literature. Experimental Economics 14, 47-83.

Cohen, L., Malloy, C.J., 2014. Friends in High Places. American Economic Journal: Economic Policy 6, 63-91.

Cox, J.C., 2004. How to Identify Trust and Reciprocity. Games and Economic Behavior 46, 260281.

Cox, J.C., Deck, C.A., 2005. On the Nature of Reciprocal Motives. Economic Inquiry 43, 623635.

Cox, J.C., Friedman, D., Sadiraj, V., 2008. Revealed Altruism. Econometrica 76, 31-69.

Dawes, R.M., 1980. Social Dilemmas. Annual Review of Psychology 31, 169-193.

Delaney, J., Jacobson, S., 2014. Those Outsiders: How Downstream Externalities Affect Public Good Provision. Journal of Environmental Economics and Management 67, 340-352.

DeScioli, P., Christner, J., Kurzban, R., 2011. The Omission Strategy. Psychological Science 22, 442-446.

Engel, C., Rockenbach, B., 2011. We Are Not Alone: The Impact of Externalities on Public Good Provision. SSRN eLibrary.

Fehr, E., Fischbacher, U., Gächter, S., 2002. Strong reciprocity, human cooperation, and the enforcement of social norms. Human Nature 13, 1-25.

Fehr, E., Kirchsteiger, G., Riedl, A., 1993. Does fairness prevent market clearing? An experimental investigation. Quarterly Journal of Economics 108, 437-459.

Fehr, E., Schmidt, K.M., 1999. A theory of fairness, competition, and cooperation. The Quarterly Journal of Economics 114, 817-868. 
Ferraro, P.J., Rondeau, D., Poe, G.L., 2003. Detecting other-regarding behavior with virtual players. Journal of Economic Behavior \& Organization 51, 99-109.

Fischbacher, U., 2007. z-Tree: Zurich Toolbox for Ready-Made Economic Experiments.

Experimental Economics 10, 171-178.

Gächter, S., 2007. Conditional cooperation: Behavioral regularities from the lab and the field and their policy implications, in: Frey, B.S., Stutzer, A. (Eds.), Economics and Psychology. A

Promising New Cross-Disciplinary Field. The MIT Press, Boston, MA.

Glöckner, A., Irlenbusch, B., Kube, S., Nicklisch, A., Normann, H.-T., 2011. Leading with(out)

Sacrifice? A Public-Goods Experiment with a Privileged Player. Economic Inquiry 49, 591-597.

Goeree, J., Holt, C., Laury, S., 2002. Private Costs and Public Benefits: Unraveling the Effects of Altruism and Noisy Behavior. Journal of Public Economics 83, 255-276.

Großer, J., Reuben, E., Tymula, A., 2013. Political Quid Pro Quo Agreements: An Experimental Study. American Journal of Political Science 57, 582-597.

Holt, C.A., Laury, S.K., 2002. Risk Aversion and Incentive Effects. American Economic Review 92, 1644-1655.

Houser, D., Kurzban, R., 2002. Revisiting Kindness and Confusion in Public Goods

Experiments. American Economic Review 92, 1062-1069.

Isaac, R.M., Norton, D.A., Pevnitskaya, S., 2013. Polarized Preferences and the Generalized Voluntary Contributions Mechanism. Florida State University.

Jacobson, S., Petrie, R., 2014. Favor trading in public good provision. Experimental Economics 17, 439-460.

Karlan, D.S., 2005. Using Experimental Economics to Measure Social Capital and Predict

Financial Decisions. The American Economic Review 95, 1688-1699.

Ledyard, J.O., 1995. Public goods: A survey of experimental research, in: Kagel, J.H., Roth, A.E. (Eds.), The Handbook of Experimental Economics. Princeton University Press, Princeton, NJ, USA.

List, J.A., 2006. The Behavioralist Meets the Market: Measuring Social Preferences and

Reputation Effects in Actual Transactions. Journal of Political Economy 114, 1-37.

Malmendier, U., Schmidt, K., 2012. You owe me. National Bureau of Economic Research.

Marwell, G., Ames, R.E., 1981. Economists free ride, does anyone else? : Experiments on the provision of public goods, IV. Journal of Public Economics 15, 295-310.

Moxnes, E., van der Heijden, E., 2003. The Effect of Leadership in a Public Bad Experiment. Journal of Conflict Resolution 47, 773-795.

Murray, C.K., Frijters, P., Vorster, M., 2015. Give and You Shall Receive: The Emergence of Welfare-Reducing Reciprocity. Institute for the Study of Labor (IZA).

Nowak, M.A., Sigmund, K., 2005. Evolution of indirect reciprocity. Nature 437, 1291-1298.

Olson, M., 1965. The logic of collective action: public goods and the theory of collective action. Harvard University Press, Cambridge, Mass.

Pevnitskaya, S., Ryvkin, D., 2013. Environmental context and termination uncertainty in games with a dynamic public bad. Environment and Development Economics 18, 27-49.

Rabin, M., 1993. Incorporating Fairness into Game Theory and Economics. American Economic Review 83, 1281-1302.

Reuben, E., Riedl, A., 2009. Public Goods Provision and Sanctioning in Privileged Groups. Journal of Conflict Resolution 53, 72-93.

Schwartz-Shea, P., 1983. Normative rhetoric and the definition of cooperation, Department of Political Science. University of Oregon, Eugene, OR, p. 89. 
Sell, J., Wilson, R.K., 1991. Levels of information and contributions to public goods. Social Forces 70, 107-124.

Sherstyuk, E., Tarui, N., Ravago, M.-L., Saijo, T., 2015. Inter-Generational Games with Dynamic Externalities and Climate Change Experiments.

Shitovitz, B., Spiegel, M., 2003. Cournot-Nash and Lindahl Equilibria in Pure Public 'Bad' Economies. Economic Theory 22, 17-31.

Sobel, J., 2005. Interdependent Preferences and Reciprocity. Journal of Economic Literature 43, 392-436.

Sonnemans, J., Schram, A., Offerman, T., 1998. Public Good Provision and Public Bad

Prevention: The Effect of Framing. Journal of Economic Behavior \& Organization 34, 143-161. Stigler, G.J., 1964. A Theory of Oligopoly. Journal of Political Economy 72, 44-61.

Van der Heijden, E., Moxnes, E., 2013. Leading by Example to Protect the Environment: Do the Costs of Leading Matter? Journal of Conflict Resolution 57, 307-326.

Wazana, A., 2000. Physicians and the pharmaceutical industry: is a gift ever just a gift? Jama 283, 373-380.

Wilson, B.J., 2008. Language games of reciprocity. Journal of Economic Behavior \& Organization 68, 365-377. 